\title{
Evaluation of the hepatotoxic potential of citalopram in rats
}

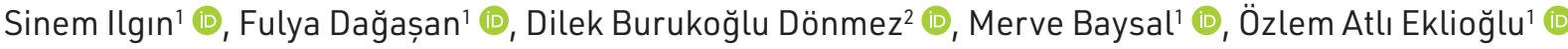 \\ ${ }^{1}$ Anadolu University, Faculty of Pharmacy, Department of Pharmaceutical Toxicology, Eskisehir, Turkey \\ ${ }^{2}$ Eskisehir Osmangazi University, Faculty of Medicine, Department of Histology, Eskisehir, Turkey
}

ORCID IDs of the authors: S.I. 0000-0001-7331-1975; F.D. 0000-0002-2136-0844; D.B.D. 0000-0002-6454-4424;

M.B. 0000-0001-8387-435X; Ö.A.E. 0000-0002-6131-3399

Cite this article as: İlgin, S., Dagasan, F., Burukoglu Donmez, D., Baysal, M., \& Atli Eklioglu, 0. (2020). Evaluation of the hepatotoxic potential of citalopram in rats. Istanbul Journal of Pharmacy, 50 (3), 188-194.

\begin{abstract}
Background and Aims: Citalopram is a selective serotonin reuptake inhibitor with a high potency which is occasionally prescribed and used to treat major depression associated with mood disorders as a first-line drug. According to the results of previous studies, evidence of hepatotoxicity related to citalopram treatment were limited and conflicting. Therefore, we aimed to evaluate the hepatotoxicity potential of sub-chronic citalopram administration.

Methods: Citalopram was administered to female rats orally in 5 and $10 \mathrm{mg} / \mathrm{kg}$ for 30 days. After the exposure period, serum aspartate aminotransferase (AST), alanine aminotransferase (ALT), total and direct bilirubin levels as biomarkers of hepatotoxicity were measured and histopathological examination of liver tissues was performed. Additionally, GSH levels of liver tissues were determined.

Results: The risk of hepatotoxicity related to citalopram was shown by significant increases of serum hepatic biomarkers, AST, $A L T$, and total bilirubin in citalopram-administered groups. According to the histopathological findings, hepatocellular necrosis, hepatic nuclear asymmetry, and disarrangement of hepatic cord cells (hepatocytes) were prominent in the $10 \mathrm{mg} / \mathrm{kg}$ citalopram-administered group. On the other hand, there was no significant difference among the groups in terms of GSH levels. Conclusion: The results suggested that the administration of citalopram might cause hepatotoxic effects, depending on the dose.

Keywords: Citalopram, hepatotoxicity, hepatic biomarker, liver histology, oxidative status
\end{abstract}

\section{INTRODUCTION}

Selective serotonin reuptake inhibitors (SSRIs) are widely used in the treatment of major depressive disorders, such as obsessivecompulsive disorders, anxiety disorders, panic disorders, and post-traumatic stress disorder (Anderson \& Edwards 2001; Locher et al., 2017). Citalopram (CTL), paroxetine, fluoxetine, and sertraline are recommended drugs in the treatment of depression (Ferguson, 2001; Sanchez, Reines, \& Montgomery, 2014). While fluoxetine is considered the first-line drug in patients under 18 years and with poor medication compliance, sertraline and CTL are chosen as the first-line drugs in patients who are elderly or have chronic diseases due to their lowest potential for drug-drug interactions (Whittington et al., 2004; Wiese, 2011; NICE, 2019; NICE, 2020). Even though CTL treatment is considered safe and tolerable for patients, the case reports indicated that severe adverse effects rarely occurred, including suicidal behavior, prolonged QTc intervals, hemorrhage, and serotonin syndrome related to CTL treatment, at therapeutic and subtherapeutic doses (Sharbaf-Shoar \& Padhy 2020).

The liver is the target for the adverse effects of many drugs because it has the largest blood supply and metabolizing enzymes (Sturgill \& Lambert 1997; Jaeschke et al., 2002). CTL is metabolized to S/R desmethylcitalopram in the liver by 
the isoenzymes CYP2C19, CYP2D6 and CYP3A4. The subsequent $\mathrm{N}$-demethylation to $\mathrm{R} / \mathrm{S}$-didesmethylcitalopram is mediated by CYP2D6 (Herrlin et al., 2003; Sangkuhl, Klein, \& Altman, 2011). Escitalopram or CTL treatment at therapeutic and subtherapeutic doses have been associated with acute liver injury (López-Torres, Lucena, Seoane, Verge, \& Andrade, 2004; Solomons, Gooch, \& Wong, 2005; Neumann, Csepregi, Evert, \& Malfertheiner, 2008; Hunfeld, ten Berge, LeBrun, Smith, \& Melief, 2010; Gessel \& Alcorn 2016). CTL seems to have the least potential for liver injury according to some studies (Voican, Corruble, Naveau, \& Perlemuter, 2014; Friedrich et al., 2016). Additionally, there have been no experimental studies related to CTL-induced hepatic adverse effects independent of other risk factors associated with hepatotoxicity. Therefore, we aimed to evaluate the hepatotoxic effects of CTL administration to rats at pharmacological doses in this study. For this purpose, levels of serum aspartate aminotransferase (AST), alanine aminotransferase (ALT), and direct and total bilirubin levels in rats were determined following oral CTL administration for 30 days. Furthermore, liver tissues of the rats were evaluated histopathologically as a biomarker of liver injury. Additionally, glutathione (GSH) levels were measured in liver homogenates to evaluate oxidative status in CTL-administered rats.

\section{MATERIALS AND METHODS}

\section{Materials}

CTL was a kind gift from IE Ulagay-Menarini Group, Turkey. The chemicals used for anesthesia were obtained from the following source: Ketamine (Ketalar ${ }^{\circledast}$ ) (Pfizer, Turkey); Xylazine (Sigma, US). Serum AST, ALT, and total and direct bilirubin levels were determined by colorimetric kits from Biolabo S.A. (France). GSH levels were measured by using the ELISA kit from Cayman Chemical Company (USA).

\section{Animals}

Female Sprague-Dawley rats (12 weeks-old) weighing 300-350 $\mathrm{g}$ were used. The animals were housed under controlled temperature $\left(22^{\circ} \mathrm{C}\right)$ and lighting (12-h light/12-h dark cycle) with free access to food and water and used in accordance with ethical recommendations of the Local Ethics Committee on Animal Experimentation of Anadolu University, Eskisehir, Turkey (File Number: 2013-14). Three experimental groups were used in the present study:

Control group: animals received distilled water via gavage for 30 days $(n=8)$.

CTL-5 group: animals received $5 \mathrm{mg} / \mathrm{kg}$ dose of CTL via gavage for 30 days $(n=8)$.

CTL-10 group: animals received $10 \mathrm{mg} / \mathrm{kg}$ dose of CTL via gavage for 30 days $(n=8)$.

The doses were determined according to the previous studies (Sekar et al., 2011; Vermoesen, Massie, Smolders, \& Clinckers, 2012; Flores-Serrano et al., 2013; Karlsson et al., 2013; Zhang et al., 2013; Vega-Rivera, Gallardo-Tenorio, Fernández-Guasti, \& Estrada-Camarena, 2016). Furthermore, clinical doses of CTL were between 10 and 60 mg/day (Bech, Tanghøj, Andersen, \& Overø 2002). The doses we have chosen were also included animal doses extrapolated from human doses by the guideline (CDER 2005). All drugs were administered at a volume of 1 $\mathrm{mL} / 100 \mathrm{~g}$ by dissolving in distilled water.

At the end of 30 days, the animals were anesthetized by an intraperitoneal injection of $60 \mathrm{mg} / \mathrm{kg}$ ketamine and $5 \mathrm{mg} /$ kg xylazine (IACUC Guidelines, 2017). Blood samples were collected from the right ventricle of the rats via syringe for the analysis of hepatic biomarkers (AST, ALT, total and direct bilirubin).

The rats were euthanized via withdrawal of large amounts of blood from the heart.

Livers were removed after euthanasia and cleaned from blood by using a phosphate buffer solution (PBS) $(8 \mathrm{~g} / \mathrm{L}$ $\mathrm{NaCl}, 0.2 \mathrm{~g} / \mathrm{L} \mathrm{KCl}, 0.2 \mathrm{~g} / \mathrm{L} \mathrm{KH}_{2} \mathrm{PO}_{4}, 1.14 \mathrm{~g} / \mathrm{L} \mathrm{Na}_{2} \mathrm{HPO}_{4}, \mathrm{pH}$ 7.4). The left lateral lobe of the liver was used to determine the levels of GSH. The liver's right superior lobe was cleared of blood and other contaminants in PBS and then fixed for histological examination.

\section{Determination of serum hepatic enzymes in rats}

After 30 minutes of allowing the blood for clotting, blood samples were centrifuged at $1,000 \mathrm{~g}$ for $15 \mathrm{~min}$ at $4^{\circ} \mathrm{C}$ to separate the serum. The enzyme analyses were performed using the commercially available kits according to the manufacturer's instructions.

\section{Histological analysis of liver tissue}

The right superior lobe of the liver was used for histological examination. The tissues were sliced into small pieces $\left(5 \mathrm{~mm}^{3}\right)$ and then fixed in a 10\% buffered formalin solution for 48 hours. They were dehydrated in a graded series of alcohols. Samples were then stained with hematoxylin and eosin and examined by light microscopy. All sections were observed under an Olympus BH-2 (Olympus Corp., Tokyo, Japan) microscope. Additionally, analyses of pathological changes were based on presence of hepatocellular necrosis, hepatic nuclear asymmetry, and disarrangement of hepatic cord cells (hepatocytes) and the changes were scored according to these criteria.

\section{Determination of GSH levels in liver tissues}

The left lateral lobe of the liver was used to determine the levels of GSH. The tissue was homogenized in a proportion of 1:20 $(\mathrm{w} / \mathrm{v})$ in cold PBS containing $50 \mathrm{~mm}$ 2-(N-morpholino) ethanesulfonic acid (MES) and $1 \mathrm{~mm}$ EDTA, pH 6-7. The samples were centrifuged at $10,000 \mathrm{~g}$ for $15 \mathrm{~min}$ at $4^{\circ} \mathrm{C}$ and the supernatant aliquots were used for the GSH assay. The analysis was performed using the commercially available kits according to the manufacturer's instructions.

\section{Statistical analysis}

Data are presented as mean \pm standard deviation. Statistical analyses were performed using one-way variance analysis (ANOVA) with the Tukey test as a post hoc test on the SPSS program (version 15) with the significance level $p<0.05$. 


\section{RESULTS}

The serum hepatic enzymes levels of control and CTLadministered rats

When the groups were compared in terms of serum AST levels, dose-related increases were observed in the CTL-administered groups compared to the control group. AST levels increased in CTL-5 and CTL-10 groups $41.11 \%$ and $47.74 \%$, respectively, when compared to the control group. No significant differences were observed among the CTL-administered groups in terms of serum AST levels.

A statistically significant increase was found in the serum ALT levels of 5 and $10 \mathrm{mg} / \mathrm{kg}$ CTL-administered groups compared to the control group. Additionally, ALT levels increased in CTL5 and CTL-10 groups $25.62 \%$ and $28.27 \%$, respectively, when compared to the control group. No significant differences were observed among the CTL-administered groups in terms of serum ALT levels.

When the groups were compared in terms of serum total bilirubin level, statistically significant increases were found in 5 and $10 \mathrm{mg} / \mathrm{kg}$ CTL-administered groups when compared to the control group. Additionally, total bilirubin levels increased in CTL-5 and CTL-10 groups $26.23 \%$ and $22.95 \%$, respectively, when compared to the control group. No significant differences were observed among the CTL-administered groups in terms of serum direct bilirubin levels. Among the CTL-administered groups, the serum total bilirubin and direct bilirubin levels did not show any statistical differences (Table 1).

\section{Table 1. The serum hepatic enzymes levels of control and CTL-administered rats.}

\begin{tabular}{|c|c|c|c|}
\hline & C & CTL-5 & CTL-10 \\
\hline $\begin{array}{l}\text { ALT } \\
\text { (U/L) }\end{array}$ & $41.64 \pm 5.27$ & $52.31 \pm 7.24^{*}$ & $53.41 \pm 7.26$ * \\
\hline $\begin{array}{l}\text { AST } \\
\text { (U/L) }\end{array}$ & $83.59 \pm 7.05$ & $117.95 \pm 24.78 *$ & $123.5 \pm 30.79$ * \\
\hline $\begin{array}{l}\text { BILD } \\
(\mathrm{mg} / \mathrm{dL})\end{array}$ & $0.034 \pm 0.013$ & $0.036 \pm 0.016$ & $0.036 \pm 0.016$ \\
\hline $\begin{array}{l}\text { BILT } \\
(\mathrm{mg} / \mathrm{dL})\end{array}$ & $0.061 \pm 0.003$ & $0.077 \pm 0.006 *$ & $0.075 \pm 0.007$ * \\
\hline \multicolumn{4}{|c|}{$\begin{array}{l}\text { Definition of abbreviations: ALT: Alanine aminotransferase, AST: } \\
\text { Aspartate aminotransferase, BILD: Direct bilirubin, BILT: Total } \\
\text { bilirubin. C: Control group; CTL-5: } 5 \mathrm{mg} / \mathrm{kg} \text { CTL administered rats } \\
\text { for } 30 \text { days group; CTL-10: } 10 \mathrm{mg} / \mathrm{kg} \text { CTL administered rats for } 30 \\
\text { days group; All data were expressed as mean } \pm \text { standard deviation; } \\
\text { Significant differences when compared with control group }(p<0.05) \text {. }\end{array}$} \\
\hline
\end{tabular}

The liver histology of control and CTL-administered rats In liver tissue obtained from the control rats, normal structural characteristics of hepatocytes and hepatic sinusoidal cells were observed histologically (Figure 1. A1 - A2).

Similar to control rats, normal hepatic structure was observed in the $5 \mathrm{mg} / \mathrm{kg}$ CTL-administered group. However, mild necrosis and disarrangement of hepatic cords were also seen in this group (Figure 1. B1 - B2).
In liver tissue of the $10 \mathrm{mg} / \mathrm{kg}$ CTL-administered rats, necrotic areas of hepatic parenchyma were identified and hepatic nuclear asymmetry was observed (Table 2). Additionally, disarrangement of hepatic cords in the portal area was more prominent than in the $5 \mathrm{mg} / \mathrm{kg}$ CTL-administered rats (Figure 1. C1 - C2).

\section{The liver GSH levels of control and CTL-administered rats}

The GSH levels of liver tissue did not show any significant difference among the groups (Table 3).

Table 2. Histopathological scoring of the tissue obtained from control and CTL-administered rats.

\begin{tabular}{|c|c|c|c|}
\hline & C & CTL-5 & CTL-10 \\
\hline $\begin{array}{l}\text { Hepato- } \\
\text { cellular } \\
\text { necrosis }\end{array}$ & - & + & +++ \\
\hline $\begin{array}{l}\text { Hepatic } \\
\text { nuclear } \\
\text { asymmetry }\end{array}$ & - & - & ++ \\
\hline $\begin{array}{l}\text { Disar- } \\
\text { rangement } \\
\text { of hepatic } \\
\text { cords }\end{array}$ & - & + & ++ \\
\hline \multicolumn{4}{|c|}{$\begin{array}{l}\text { Definition of abbreviations: C: Control group; CTL- } 5: 5 \mathrm{mg} / \mathrm{kg} \\
\text { CTL administered rats for } 30 \text { days group; CTL-10: } 10 \mathrm{mg} / \mathrm{kg} \text { CTL } \\
\text { administered rats for } 30 \text { days group. The severity of various features } \\
\text { of hepatic injury was evaluated based on those following scoring } \\
\text { schemes: - normal, + mild, ++ moderate, and +++ severe. }\end{array}$} \\
\hline
\end{tabular}

Table 3. The liver GSH levels of control and CTLadministered rats.

\begin{tabular}{|lccc|}
\hline \multicolumn{1}{|c}{ C } & CTL-5 & CTL-10 \\
\hline $\begin{array}{l}\text { GSH } \\
\text { (ug/g } \\
\text { Tissue) }\end{array}$ & $23.57 \pm 0.48$ & $24.75 \pm 1.34$ & $24.09 \pm 1.82$ \\
\hline $\begin{array}{l}\text { Definition of abbreviations: GSH: glutathione; C: Control group; CTL- } \\
\text { 5: } 5 \mathrm{mg} / \mathrm{kg} \text { CTL administered rats for } 30 \text { days group; } \text { CTL-10: } 10 \mathrm{mg} / \\
\text { kg CTL administered rats for 30 days group; All data were expressed } \\
\text { as mean } \pm \text { standard deviation. }\end{array}$ \\
\hline
\end{tabular}

\section{DISCUSSION}

The increases of AST, ALT, and total bilirubin levels accompanied by observed morphological abnormalities in liver tissue were evaluated as indicators of hepatotoxicity following CTL administration in rats. According to our study results, independent from other risk factors associated with hepatotoxicity, it is found that CTL administration at repeated pharmacological doses may cause adverse effects in the liver, depending on the dose.

Although in vitro cell culture systems and animal studies for predicting drug-induced hepatotoxicity in humans were performed, these preclinical studies may not be sufficient for predicting the potential of hepatotoxicity in humans (Kim \& Nam, 

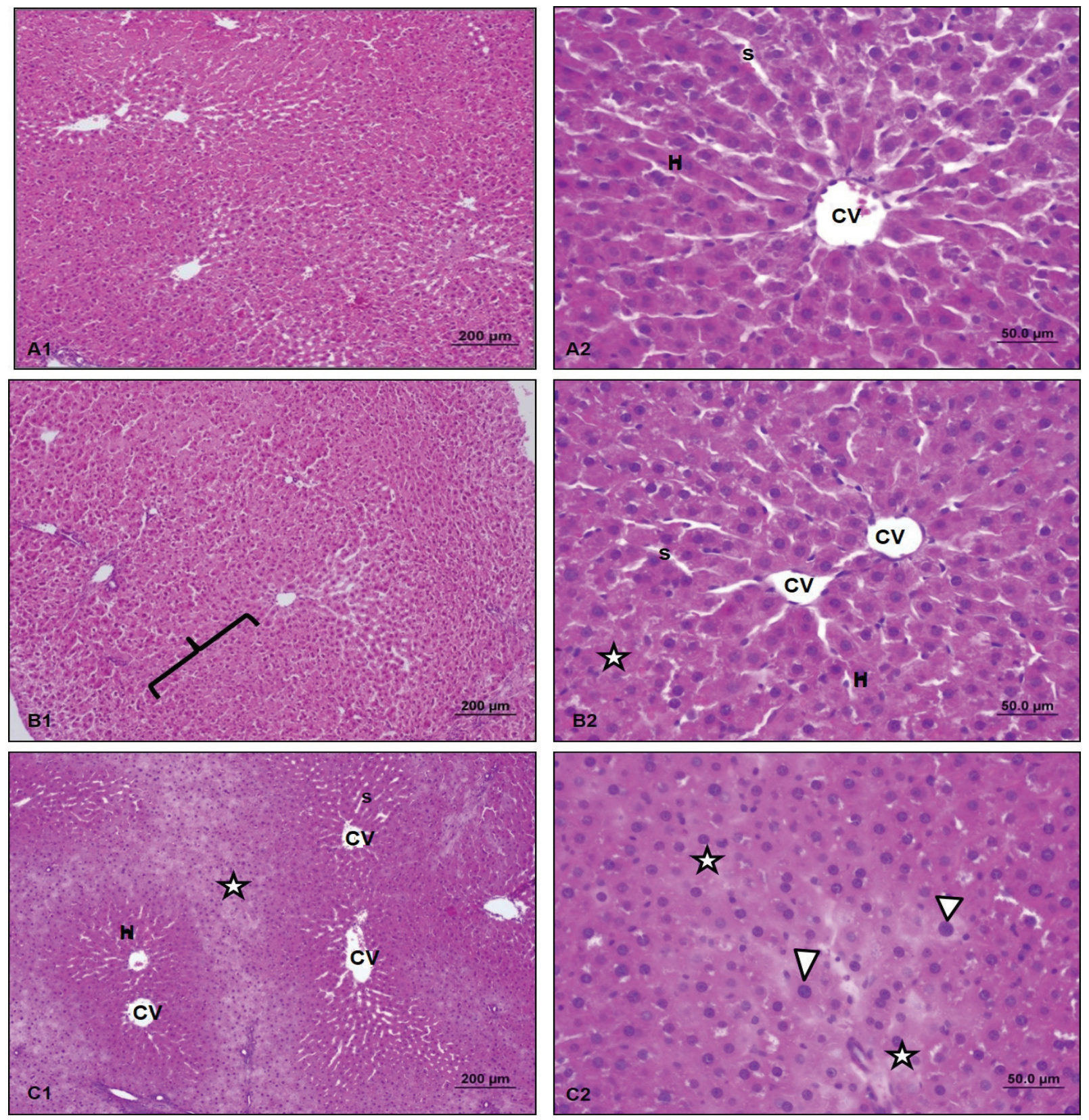

30

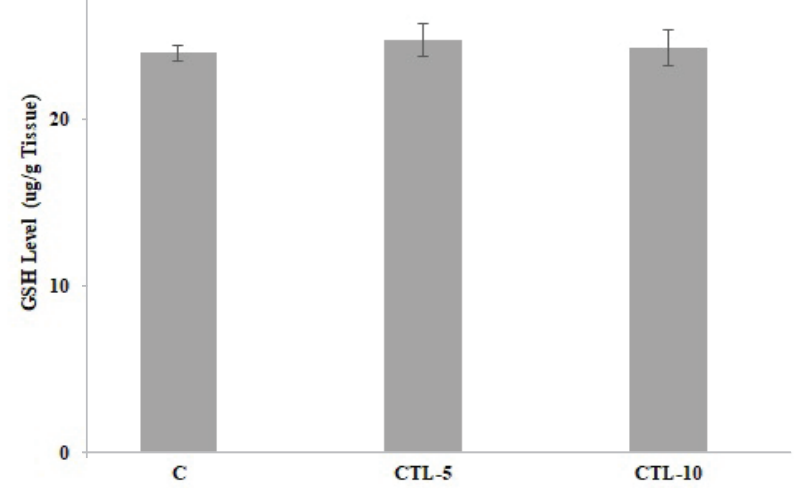

Figure 1. The liver histology of rats. A1-A2: C group showing normal hepatocytes and sinusoidal structures. (H\&E, Scale bars=200 $\mu \mathrm{m}, 50 \mu \mathrm{m})$. B1-B2: CTL-5 group showing almost normal hepatocyte structure along with necrotic areas ( $\mathbf{9})$ and disarrangement of hepatic cords ( $\left(\{)\right.$ ( $H \& E_{1}$

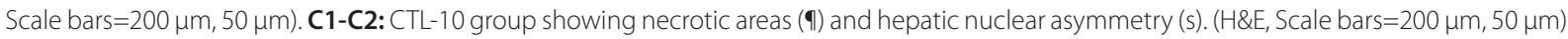
C:Control group; CTL-5:5 mg/kg CTL administered rats for 30 days group; CTL-10: $10 \mathrm{mg} / \mathrm{kg}$ CTL administered rats for 30 days group; CV:Central vein; H: Hepatocytes; S: Sinusoids 
2017; Babai, Auclert, \& Le-Louët, 2018). Drug-induced liver injury (DILI) has been approved as an important reason for the withdrawal of drugs from the market (Chen, Suzuki, Borlak, Andrade, \& Lucena, 2015; Alempijevic, Zec, \& Milosavljevic, 2017). The risk factors of DILI are classified as host-, environmental-, and drug-related factors (Campion et al., 2013; Ortega-Alonso, Stephens, Lucena, \& Andrade, 2016; Alempijevic et al., 2017). Although host-related risk factors are accepted as non-modifiable for DILI, particularly age and gender are the important factors for hepatic injury. Information about environmental risk factors such as coffee and alcohol consumption and dietary intake are limited. High daily dose, high lipophilicity, and extensive hepatic metabolism are specified as the risk factors related to DILI (Raschi \& De Ponti, 2015; Alempijevic et al., 2017). While there is a lack of specific biomarkers, traditional liver biomarkers such as AST, ALT, alkaline phosphatase (ALP), and total bilirubin are used for the diagnosis of DILI (Singh, Bhat, \& Sharma, 2011; Robles-Díaz, Medina-Caliz, Stephens, Andrade, \& Lucena, 2016; Church \& Watkins, 2017). However, increased levels of AST, ALT, and ALP following hepatocyte injury are also observed in the extrahepatic conditions (Gowda et al., 2009; Robles-Díaz et al., 2016). ALT is considered to be a more specific enzyme for liver injury than AST and ALP (Singh et al., 2011; Campion et al., 2013; Robles-Díaz et al., 2016). Increased ALT levels accompanied by increased total bilirubin levels are specifically accepted as important biomarkers for diagnosing the hepatocellular injury (Singh et al., 2011; Campion et al., 2013; Gwaltney-Brant, 2016). Additionally, in acute hepatic injury, total bilirubin can be a better indicator of disease severity compared to ALT (Dufour et al., 2000; Singh et al., 2011). In our study, increased AST, ALT, and total bilirubin levels were observed in CTL-administered groups. In addition to the case reports related to CTL-induced liver injury, the results of in vitro and in vivo studies performed by Ahmadian et al. showed hepatotoxicity findings related to CTL administration, depending on the dose (Ahmadian et al., 2017). While CTL has been expressed as one of the SSRIs with the least hepatotoxic potential in previous studies (Voican et al., 2014; Friedrich et al., 2016). However, our study highlighted the hepatotoxicity potential of CTL with clinical biochemical parameters. At this point, it could be emphasized that histopathological observations are needed to confirm the hepatotoxicity in addition to clinical biochemical parameters. Liver histology serves as an important biomarker for identifying and characterizing liver injury (Singh et al., 2011; Kullak-Ublick et al., 2017). In low dose CTL-administered rats, mild pathological findings were observed, whereas in high dose CTL-administered rats, moderate to severe morphological anomalies in liver tissue were observed. According to these results, we concluded that lowdose CTL administration induced biochemical effects without morphological changes and high-dose CTL administration caused both biochemical and morphological adverse effects in the liver.

The mechanism of CTL-induced liver injury cannot be defined, but it has been specified that cytochrome P450 enzymesmediated CTL transformation into toxic metabolite may lead to liver injury (Fredricson-Overo \& Svendsen, 1978; Ahmadian et al., 2017). At this point, it can be emphasized that GSH is responsible for detoxification of toxic metabolites. But, in our study, GSH levels of the liver did not change after CTL administration. But, GSH conjugates of CTL were not detected in other studies using human liver-derived in vitro systems (Lassila, Mattila, Turpeinen, \& Tolonen, 2015; Lassila et al., 2015). Conversely, GSH depletion have been observed in experimental models of liver injury induced with CTL (Ahmadian et al., 2017). So, it can be said that the findings indicating hepatic injury after CTL administration is not reflected by GSH levels according to our results.

\section{CONCLUSION}

In our study which was performed independently of other risk factors, we obtained findings indicating hepatic injury after CTL administration. According to our findings, clinicians should be aware of hepatotoxicity in patients under CTL treatment, and biomarkers related to hepatic injury in patients should be monitored. Particularly, CTL should be cautiously used and the minimum effective dose of CTL should be recommended in elderly patients and in patients with liver failure. Additionally, formation of toxic metabolites is considered as one of the mechanisms of CTL-induced hepatotoxicity. As it is known that the metabolic pathway of CTL includes CYP2C19, CYP3A4 and CYP2D6, dose adjustments in CYP2C19 and CYP2D6 poor metabolizer patients under the CTL treatment could be needed for the drug safety in respect to hepatotoxicity.

Ethics Committee Approval: This study was approved by the Local Ethics Committee on Animal Experimentation of Anadolu University, Eskisehir, Turkey (Number: 2013-14)

Informed Consent: Written consent was obtained from the participants.

Peer-review: Externally peer-reviewed.

Author Contributions: Conception/Design of Study- S.I., Ö.A.E.; Data Acquisition- S.I., Ö.A.E., F.D., D.B.D.; Data Analysis/Interpretation- S.I., Ö.A.E, D.B.D.; Drafting Manuscript- S.I., Ö.A.E.; Critical Revision of Manuscript- S.I., Ö.A.E.; Final Approval and Accountability- S.I., F.D., D.B.D., M.B., Ö.A.E.

Conflict of Interest: The authors have no conflict of interest to declare.

Financial Disclosure: Authors declared no financial support.

\section{REFERENCES}

- $\quad$ Ahmadian, E., Eftekhari, A., Fard, J. K., Babaei, H., Nayebi, A. M., Mohammadnejad, D., \& Eghbal, M. A. (2017). In vitro and in vivo evaluation of the mechanisms of citalopram-induced hepatotoxicity. Archives of Pharmacal Research, 40(11), 1296-1313.

- $\quad$ Alempijevic, T., Zec, S., \& Milosavljevic, T. (2017). Drug-induced liver injury: Do we know everything? World Journal of Hepatology, 9(10), 491-502.

- $\quad$ Anderson, I. M., \& Edwards, J. G. (2001). Guidelines for choice of selective serotonin reuptake inhibitor in depressive illness. Advances in Psychiatric Treatment, 7, 170-180.

- $\quad$ Babai, S., Auclert, L., \& Le-Louët, H. (2018). Safety data and withdrawal of hepatotoxic drugs. Therapie. [Epub ahead of print] https://doi.org/10.1016/j.therap.2018.02.004 
- Bech, P., Tanghøj, P., Andersen, H. F., \& Overø, K. (2002). Citalopram dose-response revisited using an alternative psychometric approach to evaluate clinical effects of four fixed citalopram doses compared to placebo in patients with major depression. Psychopharmacology (Berl), 163(1), 20-25.

- Campion, S., Aubrecht, J., Boekelheide, K., Brewster, D. W., Vaidya, V. S., Anderson, L., Burt, D., Dere, E., Hwang, K., Pacheco, S., Saikumar, J., Schomaker, S., Sigman, M., \& Goodsaid, F. (2013). The current status of biomarkers for predicting toxicity. Expert Opinion on Drug Metabolism \& Toxicology, 9(11), 1391-408.

- Chen, M., Suzuki, A., Borlak, J., Andrade, R. J., \& Lucena, M. I. (2015). Drug-induced liver injury: Interactions between drug properties and host factors. Journal of Hepatology, 63(2), 503-514.

- Church, R. J., \& Watkins, P. B. (2017). The transformation in biomarker detection and management of drug-induced liver injury. Liver International, 37(11), 1582-1590.

- Dufour, D. R., Lott, J. A., Nolte, F. S., Gretch, D. R., Koff, R. S., \& Seeff, L. B. (2000). Diagnosis and monitoring of hepatic injury. II. Recommendations for use of laboratory tests in screening, diagnosis, and monitoring. Clinical Chemistry, 46(12), 2050-2068.

- Ferguson, J. M. (2001). SSRI Antidepressant Medications: Adverse Effects and Tolerability. Primary Care Companion to the Journal of Clinical Psychiatry, 3(1), 22-27.

- Flores-Serrano, A., Vila-Luna, M., Álvarez-Cervera, F., HerediaLópez, F., Góngora-Alfaro, J., \& Pineda, J. C. (2013). Clinical doses of citalopram or reboxetine differentially modulate passive and active behaviors of female Wistar rats with high or low immobility time in the forced swimming test. Pharmacology Biochemistry \& Behavior, 110, 89-97.

- $\quad$ Fredricson-Overo, K., \& Svendsen, O. (1978). Hepatotoxicity of citalopram in rats and first-pass metabolism. Archives of Toxicology, 1, 177-180

- $\quad$ Friedrich, M. E., Akimova, E., Huf, W., Konstantinidis, A., Papageorgiou, K., Winkler, D., Toto, S., Greil, W., Grohmann, R., \& Kasper, S. (2016). Drug-Induced Liver Injury during Antidepressant Treatment: Results of AMSP, a Drug Surveillance Program. International Journal of Neuropsychopharmacology, 19(4).

- Gessel, L., \& Alcorn, J. (2016). When Good Medications Go Bad, Don't DILI Dally. Digestive Diseases and Sciences, 61 (6), 1491-1494.

- Gowda, S., Desai, P. B., Hull, V. V., Math, A. A., Vernekar, S. N., \& Kulkarni, S. S. (2009). A review on laboratory liver function tests. Pan African Medical Journal, 3, 17.

- Gwaltney-Brant, S. M. (2016). Nutraceuticals in Hepatic Diseases. In R.C. Gupta (Eds.), Nutraceuticals: Efficacy, Safety and Toxicity (pp. 7-99). London, UK: Academic Press.

- Herrlin, K., Yasui-Furukori, N., Tybring, G., Widén, J., Gustafsson, L. L., \& Bertilsson, L. (2003). Metabolism of citalopram enantiomers in CYP2C19/CYP2D6 phenotyped panel of healthy Swedes. British Journal of Clinical Pharmacology, 56(4), 415-421.

- Hunfeld, N. G. M., ten Berge, R. L., LeBrun, P. P. H., Smith, S. J., \& Melief, P. H. G. J. (2010). Hepatotoxicity related to citalopram intake: a case report. International Journal of Risk \& Safety in Medicine, 22, $1-5$.

- Institutional Animal Care and Use Committee (IACUC) (2017). Anesthesia (Guideline). Retrieved from https://animal.research. uiowa.edu/iacuc-guidelines-anesthesia

- Jaeschke, H., Gores, G.J., Cederbaum, A. I., Hinson, J. A., Pessayre, D., \& Lemasters J.J. (2002). Mechanisms of hepatotoxicity. Toxicological Sciences, 65(2), 166-176.

- Karlsson, L., Carlsson, B., Hiemke, C., Ahlner, J., Bengtsson, F., Schmitt, U., \& Kugelberg, F. C. (2013). Altered brain concentrations of citalopram and escitalopram in P-glycoprotein deficient mice after acute and chronic treatment. European Neuropsychopharmacology, 23(11), 1636-1644.
Kim, E., \& Nam, H. (2017). Prediction models for drug-induced hepatotoxicity by using weighted molecular fingerprints. BMC Bioinformatics, 18(7), 227.

Kullak-Ublick, G. A., Andrade, R. J., Merz, M., End, P., Benesic, A., Gerbes, A. L., \& Aithal, G. P. (2017). Drug-induced liver injury: recent advances in diagnosis and risk assessment. Gut, 66(6), 1154-1164.

- Lassila, T., Mattila, S., Turpeinen, M., \& Tolonen, A. (2015). Glutathione trapping of reactive drug metabolites produced by biomimetic metalloporphyrin catalysts. Rapid Communications in Mass Spectrometry, 29(6), 521-532.

- Lassila, T., Rousu, T., Mattila, S., Chesné, C., Pelkonen, O., Turpeinen, M., \& Tolonen, A. (2015). Formation of GSH-trapped reactive metabolites in human liver microsomes, S9 fraction, HepaRG-cells, and human hepatocytes. Journal of Pharmaceutical and Biomedical Analysis, 115, 345-351.

- Locher, C., Koechlin, H., Zion, S. R., Werner, C., Pine, D. S., Kirsch, I., Kessler, R. C., \& Kossowsky, J. (2017). Efficacy and Safety of Selective Serotonin Reuptake Inhibitors, Serotonin-Norepinephrine Reuptake Inhibitors, and Placebo for Common Psychiatric Disorders Among Children and Adolescents: A Systematic Review and Meta-analysis. JAMA Psychiatry, 74(10), 1011-1020.

López-Torres, E., Lucena, M. I., Seoane, J., Verge, C., \& Andrade, R. J. (2004). Hepatotoxicity related to citalopram (letter). American Journal of Psychiatry, 161(5), 923-924.

- $\quad$ Neumann, H., Csepregi, A., Evert, M., \& Malfertheiner, P. (2008). Drug-induced liver disease related to citalopram (letter). Journal of Clinical Psychopharmacology, 28(2), 254-255.

Ortega-Alonso, A., Stephens, C., Lucena, M. I., \& Andrade, R. J. (2016). Case Characterization, Clinical Features and Risk Factors in Drug-Induced Liver Injury. International Journal of Molecular Sciences, 17(5).

- $\quad$ Raschi, E., \& De Ponti, F. (2015). Drug- and herb-induced liver injury: Progress, current challenges and emerging signals of postmarketing risk. World Journal of Hepatology, 7(13), 1761-1771.

Robles-Díaz, M., Medina-Caliz, I., Stephens, C., Andrade, R. J., \& Lucena, M. I. (2016). Biomarkers in DILI: One More Step Forward. Frontiers in Pharmacology, 7, 267.

Sanchez, C., Reines, E. H., \& Montgomery, S. A. (2014). A comparative review of escitalopram, paroxetine, and sertraline: Are they all alike? International Clinical Psychopharmacology, 29(4), 185-196. Sangkuhl, K., Klein, T. E., \& Altman, R. B. (2011). PharmGKB summary: citalopram pharmacokinetics pathway. Pharmacogenetics and Genomics, 21(11), 769-772.

Sekar, S., Verhoye, M., Van Audekerke, J., Vanhoutte, G., Lowe, A. S., Blamire, A. M., Steckler, T., Van der Linden, A., \& Shoaib, M. (2011). Neuroadaptive responses to citalopram in rats using pharmacological magnetic resonance imaging. Psychopharmacology, 213(2-3), 521-531.

Sharbaf-Shoar, N., \& Padhy, R. K. (Updated 20 January 2020). Citalopram. In: StatPearls [Internet]. Retrieved from https://www.ncbi. nlm.nih.gov/books/NBK482222/

- Singh, A., Bhat, T. K., \& Sharma, O. P. (2011). Clinical Biochemistry of Hepatotoxicity. Journal of Clinical Toxicology, S:4.

Solomons, K., Gooch, S., \& Wong, A. (2005). Toxicity with selective serotonin reuptake inhibitors (letter). American Journal of Psychiatry, 162(6), 1225.

Sturgill, M. G., \& Lambert, G. H. (1997). Xenobiotic-induced hepatotoxicity: mechanisms of liver injury and methods of monitoring hepatic function. Clinical Chemistry, 43(8 Pt 2), 1512-1526.

The National Institute for Health and Care Excellence (NICE) Pathways. (Updated 1 January, 2019). Depression in children and young people: identification and management. Retrieved from https://www.nice.org.uk/guidance/ng134/documents/draftguideline 
- The National Institute for Health and Care Excellence (NICE) Pathways. (Updated 10 September, 2020). Antidepressant treatment in adults. Retrieved from

- $\quad$ https://pathways.nice.org.uk/pathways/depression/antidepressant-treatment-in-adults

- U.S. Department of Health and Human Services Food and Drug Administration Center for Drug Evaluation and Research (CDER). (July 2005). Estimating the Maximum Safe Starting Dose in Initial Clinical Trials for Therapeutics in Adult Healthy Volunteers. Retrieved from https://www.fda.gov/regulatoryinformation/search-fda-guidance-documents/estimatingmaximum-safe-starting-dose-initial-clinical-trials-therapeutics-adult-healthy-volunteers

- Vega-Rivera, N. M., Gallardo-Tenorio, A., Fernández-Guasti, A., \& Estrada-Camarena, E. (2016). The Post-Ovariectomy Interval Affects the Antidepressant-Like Action of Citalopram Combined with Ethynyl-Estradiol in the Forced Swim Test in Middle Aged Rats. Pharmaceuticals (Basel), 9(2).
- Vermoesen, K., Massie, A., Smolders, I., \& Clinckers, R. (2012). The antidepressants citalopram and reboxetine reduce seizure frequency in rats with chronic epilepsy. Epilepsia, 53(5), 870-878.

- Voican, C. S., Corruble, E., Naveau, S., \& Perlemuter, G. (2014). Antidepressant-induced liver injury: a review for clinicians. American Journal of Psychiatry, 171(4), 404-415.

- Whittington, C. J., Kendall, T., Fonagy, P., Cottrell, D., Cotgrove, A., \& Boddington, E. (2004). Selective serotonin reuptake inhibitors in childhood depression: systematic review of published versus unpublished data. Lancet, 363(9418), 1341-1345.

- Wiese, B. (2011). Geriatric Depression: The Use of Antidepressants in The Elderly. British Columbia Medical Journal, 53(47), 341347.

- Zhang, J., Dennis, K. A., Darling, R. D., Alzghoul, L., Paul, I. A., Simpson, K. L., \& Lin, R. C. (2013). Neonatal citalopram exposure decreases serotonergic fiber density in the olfactory bulb of male but not female adult rats. Frontiers in Cellular Neuroscience, 7, 67. 